swellings have not been reported. The condition is a multisystem disease with a mortality rate of up to $63 \%$, death being due to either respiratory failure or the development of a malignant lymphoma. ${ }^{2}$ An immunological basis for the disease has been suggested because of extensive immunological dysfunction found in a recent study of six patients. ${ }^{3}$ The aetiology is unknown but, interestingly, although the disease is often recognised in America, it has never been reported in Britain. It is unlikely that it has been consistently mistaken for some other infiltrative lung disease, such as Wegener's granulomatosis or histiocytosis $\mathrm{X}$, but this is possible. The radiological appearances are not diagnostic but the multisystem abnormalities and histological appearances of the lung should enable the diagnosis to be made. Steroid responsiveness appears to be a good prognostic factor, and adding cyclophosphamide may be of benefit. ${ }^{4}$

${ }^{1}$ Liebow AA, Carrington CRB, Friedman P. Lymphomatoid granulomatosis. Hum Pathol 1972;3:457-558.

${ }^{2}$ Katzenstein A-LA, Carrington CB, Liebow AA. Lymphomatoid granulomatosis. A clinicopathological study of 152 cases. Cancer 1979;43 360-73.

${ }^{3}$ Sordillo PP, Epremian B, Koziner B, Lacher M, Lieberman P. Lymphomatoid granulomatosis. An analysis of clinical and laboratory characteristics. Cancer 1982;49:2070-6.

${ }^{4}$ Fauci AS, Haynes BF, Costa J, Katz P, Wolff SM. Lymphomatoid granulomatosis. Prospective clinical and therapeutic experience over 10 years. $N$ Engl 7 Med $1982 ; 306: 68-74$.

(Accepted 8 February 1983)

Departments of Child Health and Pathology, Royal Victoria Infirmary and Freeman Hospital, Newcastle upon Tyne

A D J PEARSON, MB, MRCP, registrar

H KIRPALANI, $M B, M R C P$, registrar

T ASHCROFT, MD, MRCPATH, consultant pathologist

$\mathrm{H}$ BAIN, $M B, M R C P$, consultant paediatric cardiologist

A W CRAFT, MD, MRCP, consultant paediatrician

Correspondence to: Dr A W Craft, Children's Department, Royal Victoria Infirmary, Newcastle upon Tyne NE1 4LP.

\section{Fatal marrow aplasia associated with non-A, non-B hepatitis}

Aplastic anaemia is a rare, late complication of viral hepatitis. Over 200 cases have been reported, but only recently have the virological studies been carefully documented. Hepatitis A and hepatitis B viruses have been implicated, and two possible cases of non-A, non-B hepatitis complicated by marrow aplasia have been reported. ${ }^{1}{ }^{2}$ We report a case of hepatitis that was followed by fatal aplastic anaemia; virological studies suggested that it was non- $A$, non-B hepatitis.

\section{Case report}

A 15 year old schoolgirl was admitted to hospital with a two week history of malaise and anorexia followed by deepening jaundice with the passage of dark urine and pale stools. She had not been exposed to a jaundiced patient, drugs, or other hepatotoxic agents. She had not been abroad, had had no injections, and did not have tattoos, pierced ears, or any known source of parenteral infection.

Examination showed her to be deeply jaundiced with no signs of chronic liver disease. There was moderate smooth hepatomegaly, and the spleen was just palpable. Biochemical investigation showed a serum aspartat transaminase activity of $900 \mathrm{IU} / \mathrm{l}$, a serum bilirubin concentration of $480 \mu \mathrm{mol} / 1(28 \mathrm{mg} / 100 \mathrm{ml})$, but a normal alkaline phosphatase activity. Haemoglobin concentration and white cell and platelet counts were normal Virological screening for all hepatitis $A$ and $B$ antigens and antibodies yielded negative results on two occasions. Assay of paired sera for influenza virus, cytomegalovirus, adenovirus, Coxiella burnetii, Mycoplasma pneumoniae, and Epstein-Barr virus showed no evidence of recent or past infection by these agents. The subsequent clinical course showed a prolonged cholestatic phase; results of liver function tests were normal after 12 weeks. She resumed a normal life.

She was admitted to hospital five months after the onset of her illness and eight weeks after the biochemical resolution of her hepatitis complaining of tiredness, bruising, menorrhagia, and fainting. She had multiple petechiae and bruises, and haematological investigation showed pancytopenia with haemoglobin concentration $3.6 \mathrm{~g} / \mathrm{dl}$, corrected reticulocytes $0.5 \%$, leucocytes
$0.8 \times 10^{9} / 1$, neutrophils $0.4 \times 10^{9} / 1$, and platelets $10 \times 10^{9} / 1$ (figure). Aspiration and trephine biopsy of marrow showed severe aplasia.

Urgent marrow transplantation was considered to be necessary, and she was meanwhile given supportive treatment including norethisterone to suppress periods, and minimal filtered red cells. No suitable family donor was found, however, and while an unrelated donor was sought considerable $\Omega$ platelet support became necessary. A course of Mérieux antilymphocyte $\bar{\supset}$ globulin had no influence on her progress but was associated with mildJ serum sickness and transient convulsions. Methandienone (Dianabol) was $\$$ equally without good effect. An unrelated donor was eventually found five months after presentation, but the patient died (from disseminatede aspergillosis) at the Hammersmith Hospital during the work up for trans-" plantation. A postmortem examination showed aplasia but no evidence of chronic liver disease.

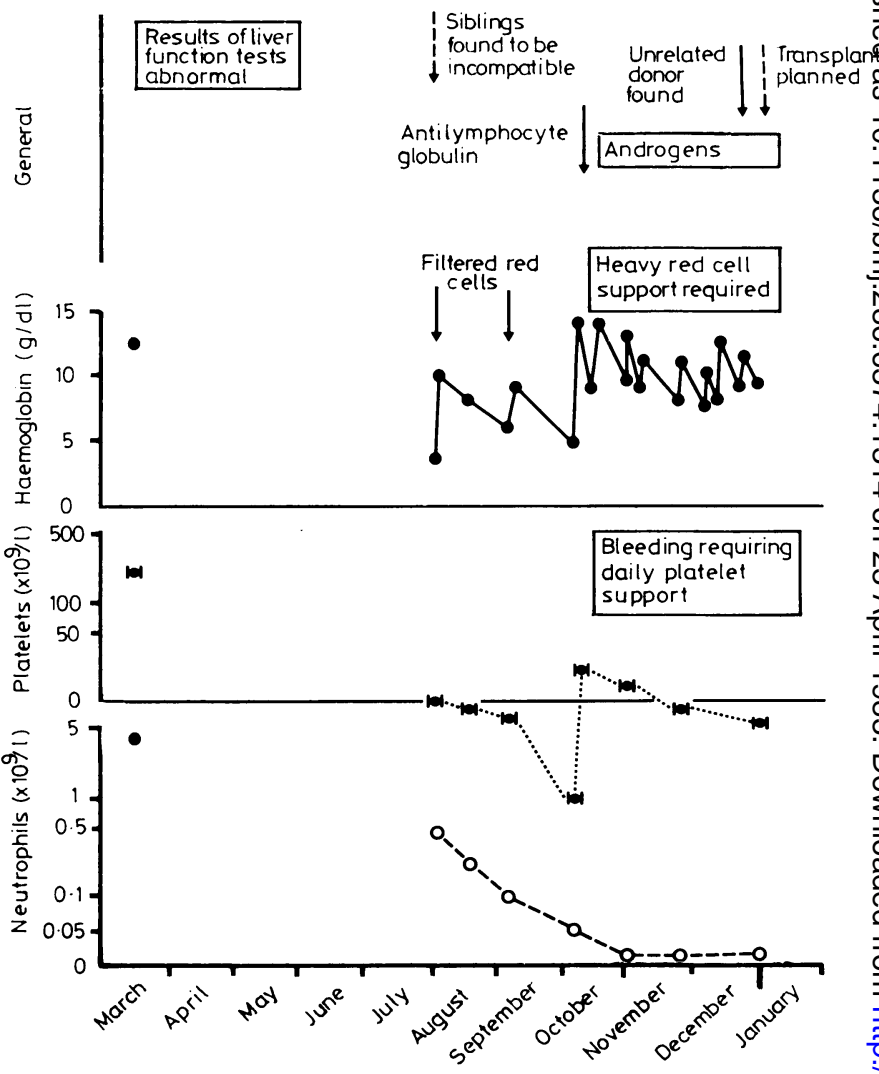

Clinical and haematological course of illness.

\section{Comment}

There appears to be a group of patients with hepatitis who develop marrow aplasia. In most cases viral studies have not been performed and hepatitis A or B has been thought to be responsible on purely epidemiological grounds, ${ }^{34}$ but in recent reports serological investif gations have provided confirmatory evidence. ${ }^{5}$ Indirect evidence is that murine hepatitis virus injected into mice causes progressive pancytopenia and that experimental administration of hepatitis $A$ in man causes transient leucopenia. ${ }^{2}$ Overall, marrow aplasia occurs in $0 \cdot 1-0 \cdot 2 \%$ of patients with hepatitis. Typically, the patient is young (mean age 20), is male rather than female, and was previously fit and healthy. The aplasia occurs a variable time after the onset of "clinical" hepatitis (mean eight weeks) and has a poor prognosis, with an overaff mortality of about $85 \%$. Marrow transplantation from histocom patible donors seems to be the treatment of choice, ${ }^{2}$ offering up to a $50 \%$ chance of successful engraftment, although experience is limited to fewer than 20 patients.

In our case the evidence for infection by non- $A$, non-B hepatition virus was indirect: there was no evidence of present or past infection with hepatitis $A$ or $B$ virus, and infection by other agents that mayb cause hepatitis was excluded, as was concomitant liver disease. Witk no definitive serological test for the non-A, non-B virus this mus remain the accepted diagnostic method. A single case study canno confirm a causal relation, but the clinical picture and the similarity to other reported cases suggests that non- $A$, non-B hepatitis is associatecte with fatal marrow aplasia. 
We are grateful to Dr J Stevenson and Dr E C Gordon Smith for allowing us to report this case.

' Perillo RP, Pohl DA, Roodman ST, Tsai CC. Acute non A non B hepatitis with serum sickness-like syndrome and aplastic anaemia. $\mathcal{F} A M A$ $1981 ; 245: 494-6$

${ }^{2}$ Firkin FC, Nicholls $\mathrm{K}$, Whelan G. Transient myeloid and erythroid aplasia associated with infectious hepatitis. $\mathrm{Br}$ Med f 1978;ii:1534.

${ }^{3}$ Camitta BM. The role of viral infections in aplastic anaemia. Haematol Bluttransfus $1979 ; 24 \cdot 39-46$.

- Hagler L, Pastore R, Bergin J, Wrensch M. Aplastic anaemia following viral hepatitis. Medicine 1975;54:139-64.

s Smith D, Gribble AS, Greenberg HB, et al. Spontaneous resolution of severe aplastic anaemia associated with viral hepatitis $\mathrm{A}$ in a six year old child. Am 7 Hematol $1978 ; 5: 247-52$.

(Accepted 4 February 1983)

\section{Seacroft Hospital, Leeds LS14 6UH}

$P$ BANNISTER, MB, MRCP, tutor in medicine

St James's University Hospital, Leeds

K MILOSZEWSKI, MD, FRCP, senior lecturer in medicine

D BARNARD, MRCP, MRCPATH, consultant haematologist

M S LOSOWSKY, MD, FRCP, professor of medicine

\section{Cigarette smoking in pregnancy and fetal hyperviscosity}

A leading article in the $B M F$ listed cigarette smoking during pregnancy as a major cause of fetal intrauterine growth retardation. ${ }^{1}$ This effect has been attributed to chronic hypoxia caused by a reduction in placentai blood flow due to the vasoconstrictor effects of nicotine and decreased oxygen availability consequent on raised concentrations of carboxyhaemoglobin in fetal and maternal blood. ${ }^{2}$ In non-pregnant adults cigarette smoking is associated with increased blood viscosity and arterial insufficiency affecting many organs. ${ }^{3}$ This study investigates the effects of maternal cigarette smoking on fetal blood viscosity and its major determinants to see if there might be a relation between the intrauterine growth retardation associated with cigarette smoking and fetal hyperviscosity.

\section{Patients, methods, and results}

Blood was collected from the umbilical veir at birth in 40 infants born to mothers who had smoked more than 20 cigarettes a day throughout pregnancy and from 40 matched non-smoking controls. Blood and plasma viscosity, packed cell volume, plasma fibrinogen concentration, and erythrocyte deformability were measured by standard techniques ${ }^{4}$ and statistical comparison of the differences in means between the two groups made using Student's $t$ test. The table gives the results. Cigarette smoking was associated with a

Haemorheological profiles of infants born to smoking and non-smoking mothers. Values are means $(S D)$

\begin{tabular}{|c|c|c|c|}
\hline & Non-smokers & Smokers & $\begin{array}{l}\text { Statistical } \\
\text { comparison }\end{array}$ \\
\hline $\begin{array}{l}\text { No of subjects } \\
\text { Gestational age (weeks) } \\
\text { Birth weight (g) } \\
\text { Packed cell volume } \\
\text { Plasma fibrinogen (g/l) } \\
\text { Plasma viscosity (mPa s) } \\
\text { Whole blood viscosity (mPa s) } \\
\text { Erythrocyte deformability index }\end{array}$ & $\begin{array}{l}40 \\
39 \cdot 4(0 \cdot 6) \\
3215(210) \\
0.50(0 \cdot 03) \\
1 \cdot 8(0 \cdot 7) \\
1.5(0 \cdot 3) \\
16.3(2 \cdot 2) \\
0.79(0.01)\end{array}$ & $\begin{array}{l}40 \\
38 \cdot 7(0.8) \\
2897(252) \\
0.56(0.04) \\
1.7(0.7) \\
1.5(0.4) \\
20 \cdot 7(2 \cdot 8) \\
0.65(0 \cdot 11)\end{array}$ & $\begin{array}{ll} & \text { NS } \\
\mathrm{p} & <0.01 \\
\mathrm{p} & 0.01 \\
\mathrm{NS} & \\
\mathrm{NS} \\
\mathrm{p}<0.01 \\
\mathrm{p}<0.02\end{array}$ \\
\hline
\end{tabular}

NS $=$ Not significant Conversion: SI to traditional units-Viscosity of plasma and whole blood: $1 \mathrm{mPa}$

$30 \%$ increase in fetal blood viscosity, this rise being compounded of a $12 \%$ increase in packed cell volume and an $18 \%$ fall in erythrocyte deformability. Neither plasma viscosity nor plasma fibrinogen values were altered.

The mean birth weight was $318 \mathrm{~g}$ lower in infants born to smoking mothers.

\section{Comment}

Maternal cigarette smoking in pregnancy results in changes in fetal blood viscosity and its major determinants similar to those described in non-pregnant adult smokers. ${ }^{3}$ When adult smokers become pregnant the large physiological variations in blood viscosity factors obscure the effects of smoking in maternal blood ${ }^{5}$ but not so in the fetus. In the extensive capillary microcirculation of the fetal placental villi, raised blood viscosity and reduced erythrocyte deformability would be apt to reduce blood flow significantly in accordance with Poiseuille's law. Reduced intravillous perfusion would combine with reduced intervillous blood flow on the maternal side of the placenta, owing to the effects of nicotine, and with the already reduced oxygen availability in both maternal and fetal blood, to cause fetal hypoxia stimulating fetal erythropoiesis with a further increase in blood viscosity leading to a vicious circle of decreasing flow and further hypoxia. This study indicates a new pathogenic pathway for the deleterious effects of maternal cigarette smoking on fetal growth and development in pregnancy.

1 Howie PW. Causes of intrauterine growth retardation. Br Med $\mathcal{J}$ 1982; 285:156-7.

2 Pirani BBK. Smoking in pregnancy. Obstet Gynecol Surv 1978;33:1-13.

${ }^{3}$ Lowe GDO, Drummond MM, Forbes CD, Barbenel JC. The effects of age and cigarette smoking on blood and plasma viscosity in men. Scott Med F 1980;25:13-7.

4 Buchan PC. Evaluation and modification of whole blood filtration in the measurement of erythrocyte deformability in pregnancy and the newborn. Br f Haematol 1980;45:97-105.

${ }^{5}$ Buchan PC. Effect of cigarette smoking on blood viscosity in pregnancy. Clinical Haemorheology 1981; 1:458.

(Accepted 27 fanuary 1983)

St James's University Hospital, Leeds LS9 7TF

PETER C BUCHAN, MD, MRCOG, consultant obstetrician and gynaecologist

\begin{tabular}{l}
\hline \hline \multirow{2}{*}{ Plasmodium malaria resistant to } \\
chloroquine in a Zambian living in \\
Zambia
\end{tabular}

Recently, chloroquine resistant Plasmodium falciparum has been acquired in east Africa by white visitors. ${ }^{2}$ We have carried out more than 25 successful in vitro macrotests, 15 in vitro microtests using capillary blood specimens, and 130 in vivo tests on the susceptibility of $P$ falciparum in Zambia to chloroquine and to the new antimalarial drug mefloquine. ${ }^{3-5}$ In the in vivo tests the patients were observed in an environment free of mosquitoes for 28-63 days after they developed malaria. Our results showed that $P$ falciparum in Zambia is generally sensitive to standard doses of chloroquine or mefloquine. Here, however, we report perhaps the first proved case of chloroquine resistant $P$ falciparum in an African living in Africa.

\section{Case report}

A 26 year old Zambian staff nurse developed clinical malaria, which was confirmed microscopically to be due to asexual $P$ falciparum, one month after she had moved to a village $1000 \mathrm{~km}$ north east of Ndola. She was treated on 10 June 1982 with two doses of $200 \mathrm{mg}$ chloroquine intramuscularly at an interval of eight hours. She refused a further injection of chloroquine the next day and instead took $600 \mathrm{mg}$ amodiaquine by mouth. Her clinical condition improved for four days, during which time she returned to Ndola. For the next 10 days she felt slightly unwell with fever and headache in the evenings; blood slides at the end of that time again showed asexual $P$ falciparum $\left(11.37 \times 10^{9}\right.$ parasites/ 1 blood $)$.

An in vitro macrotest was set up for both chloroquine and mefloquine on 24 June. The test was repeated five days after she had been given a total dose of $1.55 \mathrm{~g}(25.8 \mathrm{mg} / \mathrm{kg})$ chloroquine base by mouth over three days. Venous blood samples taken on days 3 and 4 showed plasma chloroquine concentrations of 2.89 and $2.97 \mu \mathrm{mol} / 1$ on day 3 and $3.35 \mu \mathrm{mol} / 1$ on day 4 . These concentrations were more than adequate to produce a radical cure of an infection sensitive to chloroquine-that is, one in which maturation of schizonts is completely inhibited by a concentration of $1 \cdot 0-1 \cdot 25 \mu \mathrm{mol} / \mathrm{l}$-and so this confirmed resistance. Results of daily blood smears after administration of chloroquine were: $0.66 \times 10^{9}$ asexual parasites/1 on day $3,0.42 \times 10^{9} / 1$ on day $4,2.55 \times 10^{9} / 1$ on days 5 and 6 , and $4.35 \times 10^{9} / 1$ on day 7 . Because 